\title{
Medical Image of the Week: Fast-growing Primary Malignant Mediastinal Mixed Germ Cell Tumor
}

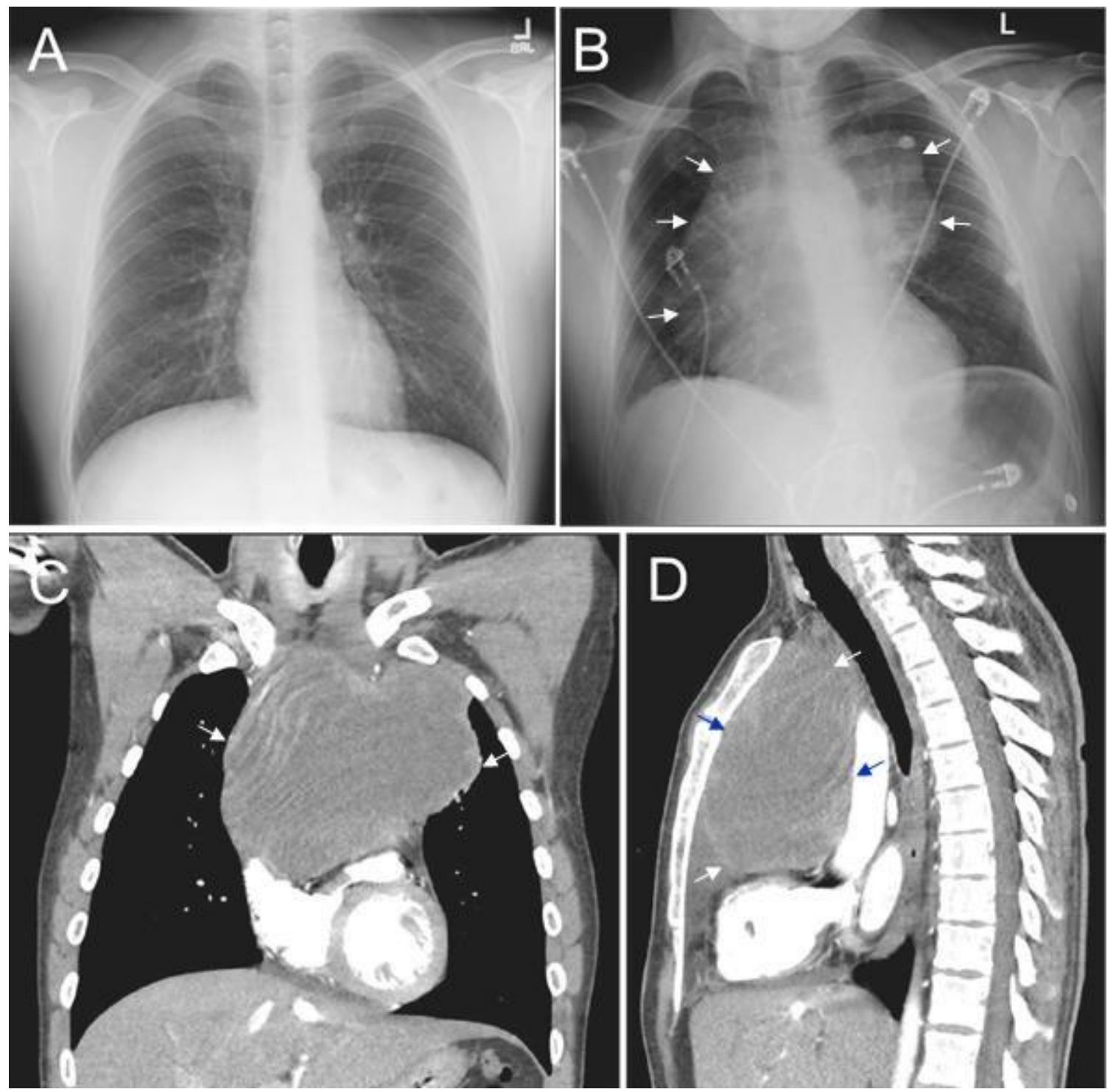

Figure 1. A: Chest radiograph taken 3 months prior to presentation. B: Chest radiograph showing large mediastinal mass (arrows). C: Coronal view of thoracic

CT in soft tissue windows showing large mediastinal mass (arrows). D: Lateral view of thoracic CT in soft tissue windows showing large mediastinal mass (arrows).

A 28-year-old man presented with progressive hemoptysis for two weeks. He had fever, cough, and night sweats for one month prior to admission that was treated as influenzae, bronchitis and/or pneumonia. He had started to experience anorexia, dysphagia, fatigue, a 30-pound weight loss, panic attacks, and the new onset of hypertension during the 3 months prior to admission. He also had intermittent middle chest pain that was aggravated by coughing for 5 months, but 
a cardiac catherization two months prior failed to show an abnormality. The chest $x$-ray and CT scan on this admission demonstrated a large $15 \mathrm{~cm}$ anterior mediastinal mass exerting a mass effect on the heart and mediastinal lymphadenopathy (Figure 1-B,C,D) which were absent on a chest $x$-ray performed 3 months prior to admission (Figure 1A). Core biopsy and immunohistochemical staining revealed a mixed germ cell tumor with components of seminoma and yolk-sac tumor. He was started on chemotherapy, to which he responded well. The malignant mediastinal germ cell tumor in this case is fast-growing and most likely of extragonadal origin. The majority of tumors occur in men between 20 and 35 years (1). The symptoms of these tumor and nonspecific as described in our case, which may lead to a low index of suspicion of malignant tumor with resultant delayed diagnosis.

Yufei Tian, Stella Pak, and Qiang Nai Department of Medicine University of Toledo Medical Center Toledo, Ohio USA

\section{Reference}

1. Carter BW, Marom EM, Detterbeck FC. Approaching the patient with an anterior mediastinal mass: a guide for clinicians. J Thorac Oncol. 2014 Sep;9(9 Suppl 2):S102-9. [CrossRef] [PubMed] 